\title{
Volatility spillover effect between financial markets: evidence since the reform of the RMB exchange rate mechanism
}

Zhengde Xiong ${ }^{1,2^{*}}$ and Lijun $\operatorname{Han}^{1}$

\footnotetext{
* Correspondence: hnxzd@126.com ${ }^{1}$ School of Business Administration, Hunan University, Changsha 410082, China

${ }^{2}$ Center of Finance and Investment Management, Hunan University, Changsha 410082, China
}

\begin{abstract}
The volatility spillover effect between the foreign exchange and stock markets has been a major issue in economic and financial studies. In this paper, GC-MSV model was used to study the spillover effect between the foreign exchange market and the stock market after the reform of the RMB exchange rate mechanism. The empirical results show that there is a negative correlation of dynamic price spillovers between the foreign exchange and stock markets. There are asymmetric volatility spillover effects between these two markets for both RMB stages_continued RMB appreciation or constant RMB shock (a significant reduction in appreciation). However, this has been reduced over time. In conclusion, The RMB exchange rate is a key variable that can affect the internal and external equilibrium of the national economy in an open economic environment, and the stock market is capable of quickly reflecting subtle changes in the real economy. In order to keep the stability of the financial markets and the healthy and rapid development of national economy, some suggestions were proposed.
\end{abstract}

Keywords: Financial markets; Volatility spillover effect; GC-MSV model

\section{Background}

The volatility spillover effect of financial markets has always been a focus of the financial supervision regulation department and scholars at home and abroad. Along with China extending the reform of the foreign exchange management system and shareholder structuring, the foreign exchange and stock markets gradually returned to market-oriented operations and the interactions between these markets began to appear as associated features. Together with the acceleration of international financial integration and liberalization, the volatility spillover effect of China's foreign exchange and stock markets has gradually increased. Relative to the variable's first moment relationship reflected in the price spillover effect in financial markets, the volatility spillover effect reflects the variable's second moment relationship, in which market volatility is influenced not only by its own early stage but also by volatility coming from other markets. The volatility spillover effect exists widely in different types of financial markets in different regions. It is an important aspect of volatility in all financial markets and instigates the volatility conduction process from one financial market to another Chen et al. 2009.

(C) 2015 Xiong and Han. Open Access This article is distributed under the terms of the Creative Commons Attribution 4.0 International License (http://creativecommons.org/licenses/by/4.0/), which permits unrestricted use, distribution, and reproduction in any medium, provided you give appropriate credit to the original author(s) and the source, provide a link to the Creative Commons license, and indicate if changes were made. The Creative Commons Public Domain Dedication waiver (http://creativecommons.org/publicdomain/zero/1.0/) applies to the data made available in this article, unless otherwise stated. 
Currently, research on the volatility spillover effect has most often been focused on financial markets in developed countries, but less often in emerging counties. Kanas (2000) studied the volatility spillover effect between the exchange rate and the stock price of subjects in six industrial countries-the United States, the United Kingdom, Japan, German, France, and Canada. The results showed that except Germany, in other countries, there was a significant volatility spillover effect from the stock market to the exchange market; however, the reverse effect, exchange market to stock market, was faint. Yang \& Doong (2004), on the basis of Kanas, expanded the sample size to G-7 countries and arrived at the same conclusions as Kanas. Chen et al. (2004) explained the phenomenon of these differences in market volatility transmission between various countries. He thought, in bigger and more mature countries, domestic factors influenced the financial markets more strongly than foreign factors; therefore, the influences of volatility between the stock market and the exchange market became faint to some extent. Chang et al. (2009) performed an empirical study using the GJR-GARCH model. Their results indicate that there is an asymmetric threshold and a co-integration relationship between the exchange and the stock markets. Shusong \& Min (2009) added the interest margin as an exogenous variable to two variables in the EGARCH model to study the dynamics between China's exchange and stock markets. Their conclusions were that there is an asymmetric volatility spillover effect from the stock market to the exchange market, but a symmetric volatility spillover effect from the exchange market to the stock market. Using a co-integration Granger causality test, Zhizhen \& Xiuquan (2010) empirically tested the interaction of the exchange and stock markets. The results confirmed that there is a long-term and stable relationship between the exchange and stock markets and that there is a one-way price spillover effect and a one-way volatility spillover effect between these markets. Xinling \& Peng (2011) analyzed the volatility spillover effect of China's exchange rate and stock price. They found that a two-way volatility spillover effect exists between the exchange rate and the stock price; however, these two-way fluctuations are, to some degree, asymmetrical so that the effect of the exchange rate volatility on stock price volatility is less significant than the effect of stock price volatility on exchange rate volatility. This was different from previous study conclusions that stated that the volatility spillover effect mainly existed between the exchange and stock markets. The empirical study of Alaganar \& Bhar (2007) found that sample data of the exchange rate significantly impacted the diversified-portfolio of the United States stock market on the first and second order, with the assessment of the exchange rate less likely to be affected by the stock index. However, the exchange rate volatility information impacted significantly on the investment portfolio and investor decisions in the stock market. Choi (2009), using the multivariables EGARCH model, measured the volatility spillover between the exchange and stock markets of New Zealand after the Asia financial crisis in 1997. The study showed that the volatility of the stock price had a spillover effect on the three indices in the whole sample range. Wong \& Li (2010) assigned the Asia financial crisis in 1997 and the United States financial crisis in 2007 as the important external impacts for analysis, and then arrived at the idea that during a financial crisis, having the exchange rate remain relative stable would be important for the stock market to function normally. Chi et al. (2012) performed an empirical study on the volatility spillover effect between the exchange and stock markets through multiresolution wavelet analysis. They found 
that in different trading periods, the volatility spillover effect demonstrated no coherence over a short time, indicating only a one-way volatility spillover from the stock market to the exchange market. However, as the transaction cycles grew, it showed two-way volatility spillover effects.

As for the research methods, previous study methods have been restricted to cointegration tests, Granger causality tests, impulse response function, and a variancebased information decomposing model to investigate the price volatility spillover effect of the exchange and stock markets. Studies on the volatility spillover effect have been limited to using the GARCH model. It is a future trend to use better, advanced measuring methods to test the volatility of financial time and the time-varying characteristics of the spillover effect. With the acceleration of global integration, financial markets of developing countries have achieved rapid progress, the market scale expanding, and the information transmission mechanisms, constantly improving the trades between developing and developed countries prompt increase ties between their financial markets. It is particularly important to research the volatility spillover effect in different types of financial markets in different regions through the stochastic volatility model.

\section{Methods}

The main econometric models to estimate volatility characteristics and spillovers between financial markets are the autoregressive conditional heteroskedasticity (ARCH) model and stochastic volatility (SV) model. As one of the mainstream models for estimating spillover effects between financial markets, the ARCH model has been widely used and extended. By comparison, the application of the SV model has been limited for a long time because of its shortcomings in parameter estimation and in the accurate likelihood function.

Chinese scholars such as Suhong et al. 2003 have performed several studies on the goodness of the fit of these two models. By comparing their capabilities for describing financial time series data, they drew the conclusion that the SV model can achieve better fitting effects for financial data than the $\mathrm{ARCH}$ model. Unlike $\mathrm{ARCH}$, which regards the volatility equation as a fixed function with past disturbance and conditional variance, the SV model considers volatility equation as a random variable, more in line with modern financial theory, and doing so, greatly increases the flexibility of evolution equations with conditional variance. Therefore, this paper selected the SV model to conduct its empirical research.

The SV model was first proposed by Taylor (1986) This model considered the noise process of the variance equation and that fluctuation was determined via an unobserved stochastic process. Therefore, it is considered to be a better approach when combined with the characteristics such as high peak and fat tail of financial data, and it is more suitable to describe financial time series. Since the seminal work of the SV model, it has been variously extended and applied to many financial variables. The Granger causality-MSV (GC-MSV) is a binary SV model that contains a model parameter matrix $\Phi$, which covers the most important economic variables that can be used to explain the persistence and volatility spillover effects of the exchange rate and the stock return series in empirical studies. It can also identify the lead-lag relationship between variables. If $\phi_{12}=0$ or $\phi_{21}=0$, then we can judge that unilateral volatility spillovers exist between these two markets. In this paper, the GC-MSV model is employed to examine 
the volatility spillover effects between China's foreign exchange and stock markets. The formulation can be defined as follows.

$$
\begin{aligned}
& y_{t}=\Omega_{t} \varepsilon_{t}, \quad \varepsilon_{t} \stackrel{i i d}{\sim} N\left(0, \Sigma_{\varepsilon}\right), \\
& h_{t+1}=\mu+\Phi\left(h_{t}-\mu\right)+\eta_{t}, \quad \eta_{t} \stackrel{i i d}{\sim} N\left(0, \operatorname{diag}\left(\sigma_{\eta_{1}}^{2}, \sigma_{\eta_{2}}^{2}\right)\right)
\end{aligned}
$$

In equation (1), $y_{t}=\left(y_{1 t}, y_{2 t}\right)^{\prime}$ represents the return series set at time t. $\Omega_{t}=$ $\operatorname{diag}\left(\exp \left(h_{t} / 2\right)\right)$ is a diagonal matrix constructed by binary standard deviation, where $h_{t}=\left(h_{1 t}, h_{2 t}\right)^{\prime}$ and $h_{0}=\mu$. In most cases, $h_{t}=\ln \sigma_{t}^{2}$ is used to test fluctuations in the series. $\varepsilon_{t}=\left(\varepsilon_{1 t}, \varepsilon_{2 t}\right)^{\prime}$ represents the disturbance process that is normally distributed with zero mean and a variance of $\Sigma_{\varepsilon}$. Here, $\Sigma_{\varepsilon}=\left(\begin{array}{cc}1 & \rho_{\varepsilon} \\ \rho_{\varepsilon} & 1\end{array}\right)$ depicts the correlation coefficient matrix that never changes over time $\mathrm{t}$.

In equation (2), $\mu=\left(\mu_{1 t}, \mu_{2 t}\right)^{\prime}$ is a parameter vector. $\phi_{12}$ and $\phi_{21}$ are the most important parameters in matrix $\Phi=\left(\begin{array}{ll}\phi_{11} & \phi_{12} \\ \phi_{21} & \phi_{22}\end{array}\right) \cdot \phi_{12}$ denotes volatility spillover effects from the stock market to the foreign exchange market and $\phi_{21}$ denotes volatility spillover effects from the foreign exchange market to the stock market. $\eta_{t}=\left(\eta_{1 t}, \eta_{2 t}\right)^{\prime}$ represents normally distributed white noise.

In the selection of the estimating methods for the model, this paper uses the method of Markov Chin Monte Carlo (MCMC), based on Gibbs sampling, to estimate model parameters. The MCMC method possesses good statistical properties under a situation with a limited sample and can overcome the static and high dimension characteristics of a traditional model. It has been widely used in financial analysis and proved to be an effective method to estimate the MSV model. It makes simulations dynamic by introducing the Markov process into a Monte Carlo simulation. In fact, the MCMC method is a special type of Monte Carlo integration method. Its basic idea is to create a Markov chain with stationary distribution $\pi(x)$ and get the sampling of $\pi(x)$. After that, statistical inference is performed based on the sampling, among which the MCMC method using Gibbs sampling is the most widely deployed method.

\section{Results}

\section{Data for empirical research}

In this paper's empirical study, two variables are involved-the RMB exchange rate and the stock market price. In the selection of the RMB exchange rate index, we can learn from the existing literature that the nominal exchange rate and the effective exchange rate are the most common indices that are selected for sample data. A study conducted by Bodnar and Gentry (1993) found that although the real exchange rate eliminated the inflation rate, the market could not respond in a timely fashion to the changes in real exchange rates. In fact, the market was more sensitive to the changes in the nominal exchange rate. In addition, considering that the U.S. dollar is China's major foreign trade settlement currency and dollar reserves play an important role in China's foreign exchange reserve, we selected the RMB/US dollar nominal exchange rate (denoted by PER) as the sample index exchange rate, and the sample data were obtained from the SAFE website (www.safe.gov.cn). 
In terms of the selection of the stock market price index, this index is regarded as the most typical indicator, reflecting the overall condition of the stock market, and the Shanghai and Shenzhen Stock Exchanges are the only two national stock markets in mainland China. However, there is a higher degree of market openness and maturity in the Shanghai Stock Exchange than in the Shenzhen Stock Exchange, and thus, it can undoubtedly reflect more market information. Moreover, considering that the closing price is the most representative, this paper selected the daily closing prices for the Shanghai Composite Index (Denoted by PSH) as the sample index of the stock market price. Sample data were obtained from the China Yahoo Finance website (finance.cn.yahoo.com).

First, to eliminate the heteroscedasticity phenomenon of time-series, we took the natural logarithm of the sample data, and then we obtained the market return series using difference calculations. The formula follows.

$$
R_{i, t}=100 \times\left(\ln P_{i, t}-\ln P_{i, t-1}\right), i=\mathrm{ER}, \quad \mathrm{SH}
$$

where $R_{i, t}$ denotes the returns of market $\mathrm{i}$ on the date of $\mathrm{t}, P_{i, t}$ depicts the price of market $\mathrm{i}$ on the date of $\mathrm{t}$, and $\mathrm{i}$ represents ER (foreign exchange market) or $\mathrm{SH}$ (Shanghai stock market).

According to the existing literature, models that theoretically elaborate the spillover effects between the foreign exchange market and the stock market are mainly flow Dornbusch and Fischer 1980- and stock-oriented models Branson 1983. These two classic theoretical models propose different views based on different perspectives. The former assumes that the fluctuations of exchange rates will lead to the volatility of stock prices, namely that there exists a unidirectional causality from the exchange rate to the stock price. This model is mainly used in researches that target countries with high foreign trade dependence as the research subjects. In contrast, the latter model assumes that stock price volatility will cause exchange rate fluctuation. This model more sensibly explains the countries with a high degree of financial liberalization.

Before the reform of the RMB exchange rate mechanism, China was adopting a market-based, single, managed floating exchange rate system. Although there are studies on the relationships between financial markets, discussions on exchange rate fluctuations have been rare because the exchange rate has not been flexible enough. In addition, at that time, China's stock market was still at the starting phase, the operation mechanism of the stock market needed further improvement, and the information transmission mechanism between the foreign exchange market and the stock market was not open. Studies in this field apparently lacked corresponding economic explanation and made no sense in terms of China's economy. This could explain why domestic studies on the interactive relationship between the foreign exchange and stock market were rare during this period. On July 21, 2005, China began to implement a market-based, managed floating exchange rate regime with reference to a basket of currencies, which meant that RMB was no longer solely pegged to the US dollar. As a result, the RMB exchange rate mechanism became more flexible. With constant improvement of the exchange rate mechanism, the basic system construction of China's stock market gradually standardized, and the steady improvement in the economic environment made it possible to study the volatility spillover effect between China's foreign exchange and stock market. 
Since the reform of the RMB exchange rate mechanism on July 21, 2005, the overall trend in RMB has been continuously appreciated. However, it has shown different characteristic at different time intervals. The whole process of exchange rate fluctuation could be divided into two stages. The first stage was set as the period from July 21, 2005 to July 16, 2008. During this time, the RMB experienced constant appreciation. For convenience, we call this the stage of continued RMB appreciation. The second stage was set as the period from July 1, 2008 to April 30, 2010. During this period, the pace of $\mathrm{RMB}$ appreciation was significantly reduced. We call it the stage of constant RMB shock. Because the premise and assumptions of the flow-oriented model are in line with China's economic environment, the starting point of this study is based on the perspective of exchange rate fluctuations. Hence, the whole time series has been divided into two stages according to the above trends in changes in the RMB rate compared with the US dollar. The spillover effects in each stage between the foreign exchange and the stock market have been examined separately to discover the difference.

\section{Unit root test}

To study the spillover effect in the stage of continued RMB appreciation, the first thing we did was to have the return series in that period tested by unit root test. In this paper, we examined the first-order difference sequence $\left(R_{i}\right)$ Brooks and Gelman 1998 by applying the ADF unit root test. The number of lags used in the test was determined by AIC criterion. Two types of time series were tested: the time series constructed by the constant term only and the time series constructed by the constant term and the trend term. Table 1 indicated that $R_{E R}$ and $R_{S H}$ (they were the first-order difference sequences) are stationary sequences in the above mentioned types of time series at significance levels of 10,5 , and $1 \%$. Namely, $R_{E R}$ and $R_{S H}$ obey $I(0)$. Thus, they can be used directly to estimate the parameter of the return series of the foreign exchange and stock markets.

Similarly, two types of time series were tested in the stage of constant RMB shock: time series constructed by a constant term only and time series that are constructed by a constant term and a trend term.

As we can see in Table $2, R_{E R}$ and $R_{S H}$ are stationary sequences in the abovementioned types of time series at significance levels of 10,5 , and $1 \%$. Namely, both $R_{E R}$ and $R_{S H}$ obey $I(0)$. Thus, they can be used directly to estimate the parameter of the return series of the foreign exchange market and the stock market.

Table 1 The results of unit root test

\begin{tabular}{llllllll}
\hline Variables & $\begin{array}{l}\text { Type } \\
(\mathrm{C}, \mathrm{T})\end{array}$ & $\begin{array}{l}\text { ADF } \\
\text { values }\end{array}$ & $\begin{array}{l}\text { Critical value at 1 \% } \\
\text { significance level }\end{array}$ & $\begin{array}{l}\text { Critical value at } \\
5 \% \text { significance } \\
\text { level }\end{array}$ & $\begin{array}{l}\text { Critical value at } \\
10 \% \text { significance } \\
\text { level }\end{array}$ & $\begin{array}{l}P \text { values } \\
\text { Conclusion }\end{array}$ \\
\hline$R_{E R}$ & $(1,0)$ & -26.6842 & -3.4392 & -2.8653 & -2.5688 & 0.0000 & Smooth \\
$R_{S H}$ & $(1,0)$ & -27.0766 & -3.4392 & -2.8653 & -2.5688 & 0.0000 & Smooth \\
$R_{E R}$ & $(1,1)$ & -21.1644 & -3.9708 & -3.4161 & -3.1303 & 0.0000 & Smooth \\
$R_{S H}$ & $(1,1)$ & -27.2565 & -3.9708 & -3.4160 & -3.1303 & 0.0000 & Smooth \\
\hline
\end{tabular}


Table 2 The results of unit root test

\begin{tabular}{llllllll}
\hline Variable & $\begin{array}{l}\text { Type } \\
(\mathrm{C}, \mathrm{T})\end{array}$ & $\begin{array}{l}\text { ADF } \\
\text { values }\end{array}$ & $\begin{array}{l}\text { Critical value at } \\
1 \% \text { significance } \\
\text { level }\end{array}$ & $\begin{array}{l}\text { Critical value at } \\
5 \% \text { significance } \\
\text { level }\end{array}$ & $\begin{array}{l}\text { Critical value at } \\
10 \% \text { significance } \\
\text { level }\end{array}$ & $\begin{array}{l}P \text { values } \\
\text { Conclusion }\end{array}$ \\
\hline$R_{E R}$ & $(1,0)$ & -23.1662 & -3.4451 & -2.8679 & -2.5702 & 0.0000 & Smooth \\
$R_{S H}$ & $(1,0)$ & -20.4621 & -3.4451 & -2.8679 & -2.5702 & 0.0000 & Smooth \\
$R_{S H}$ & $(1,1)$ & -23.1666 & -3.9792 & -3.4202 & -3.1327 & 0.0000 & Smooth \\
$R_{S H}$ & $(1,1)$ & -20.4508 & -3.9792 & -3.4202 & -3.1327 & 0.0000 & Smooth \\
\hline
\end{tabular}

\section{Discussion}

Volatility spillovers during the stage of continued RMB appreciation

\section{Convergence diagnosis}

After having finished unit root tests on the data, we used the GC-MSV model to empirically research volatility spillover effects between the foreign exchange and the stock markets during the stage of continued RMB appreciation. The convergence of parameters should be tested first. The Gelman-Rubin statistic is given by the Win BUGS software, which is also referred to as the GR statistics. Various iteration chains would be formed if multiple sets of initial values of GR statistics were input in the software. Moreover, the iteration chains would tend to overlap when the GR statistic approaches 1.0 for the increasing iteration numbers, which implies that the convergence of the model parameters has been reached.

In this process of Gibbs sampling, we tried multiple groups of iterations and eventually found that the desired statistic effect could be achieved when the iteration number equaled 40,000. Therefore, we conducted 40,000 iterations on the model parameters for the stage of continued RMB appreciation. However, to ensure the convergence of the estimated results of the model parameters, we abandoned the former 20,000 iterative samples for annealing and stored the last 2000 iterative samples for parameter estimation. The results of the convergence diagnosis for the GR statistics of the unknown parameters $\left(\mu_{1}, \mu_{2}, \phi_{11}, \phi_{22}, \phi_{12}, \phi_{21}, \rho_{\varepsilon}, \sigma_{\eta 1}, \sigma_{\eta 2}\right)$ show that the GR statistics of each parameter approaches 1.0 with increasing iteration numbers. This indicates that the samples reached convergence and can ensure the accuracy of parameter estimation.

\section{The estimation results and analysis}

After ensuring the convergence of the model parameters, we used the estimation results of the parameters to explain the spillover effects. The mean, standard deviation, MC-error, $2.5 \%$ fractile, median value, and $97.5 \%$ fractile of each parameter $\left(\mu_{1}, \mu_{2}\right.$, $\left.\phi_{11}, \phi_{22}, \phi_{12}, \phi_{21}, \rho_{\varepsilon}, \sigma_{\eta 1}, \sigma_{\eta 2}\right)$ in the GC-MSV model are given in Table 3.

Table 3 Estimation results of parameters in the GC-MSV model

\begin{tabular}{llllllllll}
\hline Parameters & $\mu_{1}$ & $\mu_{2}$ & $\phi_{11}$ & $\phi_{22}$ & $\sigma_{\eta 1}$ & \multicolumn{1}{l}{$\sigma_{\eta 2}$} & \multicolumn{1}{c}{$\rho_{\varepsilon}$} & \multicolumn{1}{l}{$\phi_{12}$} & $\phi_{21}$ \\
\hline Mean & -6.953 & 0.9594 & 0.9976 & 0.9773 & 0.1663 & 0.1519 & -1.1015 & 0.1207 & 0.2143 \\
Standard deviation & 0.4500 & 0.2127 & 0.0014 & 0.0090 & 0.0229 & 0.0249 & 0.0301 & 0.0189 & 0.0190 \\
MC error & 0.0197 & 0.0076 & 0.0001 & 0.0003 & 0.0012 & 0.0014 & 0.0004 & 0.0001 & 0.0001 \\
2.5 \% fractile & -7.8270 & 0.5249 & 0.9941 & 0.9568 & 0.1271 & 0.1126 & -0.1604 & 0.0845 & 0.1855 \\
Median & -6.9580 & 0.9639 & 0.9979 & 0.9784 & 0.1643 & 0.1496 & -0.1014 & 0.1196 & 0.2017 \\
97.5 \% fractile & -6.0640 & 1.3760 & 0.9983 & 0.9916 & 0.2144 & 0.2051 & -0.0428 & 0.1583 & 0.2674 \\
\hline
\end{tabular}


As can be seen from Table 3, the standard deviation and the MC error of each parameter are fairly small, but MC errors are much smaller than the standard deviation. This, once again, validates the convergence of the sample. The estimation results of parameters $\phi_{12}$ and $\phi_{21}$ are 0.9976 and 0.9773 , respectively, indicating that the exchange rate changes and stock market volatility possess the characteristic of persistence. The volatility spillover effect from stock to foreign exchange markets is captured by the parameter $\phi_{12}$, with the estimated value of 0.1207 . Similarly, the volatility spillover effect from the foreign exchange market to the stock market is captured by parameter $\phi_{21}$, with the estimated value 0.2143 . On the one hand, $\phi_{12}$ and $\phi_{21}$ have passed the convergence test and are significantly different from zero. This indicates that there is a tight linkage between stock return series and exchange rates in terms of the conditional secondary moments of relevant distributions, which is known as volatility spillovers. On the other hand, the estimated value of parameter $\phi_{12}$ is less than that of parameter $\phi_{21}$, implying that the influence of exchange rate fluctuations on the stock market is stronger than the influence of stock price volatility on the foreign exchange market.

The above empirical conclusions can be explained economically by the following reasons. First, since the reform of the exchange rate system, the continuous appreciation and high expectations for RMB appreciation brought in massive speculative capital inflows, coupled with China's high reliance on foreign trade; this led to the stock market's increased sensitivity to exchange rate fluctuations. Second, the implementation of a managed floating exchange rate regime strengthened the control of capital accounts and to some extent, limited the exchange of information between the exchange and stock markets, ultimately resulting in an insignificant volatility spillover effect from the stock to the foreign exchange market.

When estimating the GC-MSV model, the posterior distribution kernel density estimation curve of the parameters $\left(\mu_{1}, \mu_{2}, \phi_{11}, \phi_{22}, \phi_{12}, \phi_{21}, \rho_{\varepsilon}, \sigma_{\eta 1}, \sigma_{\eta 2}\right)$ can also be obtained. As can be seen from Fig. 1, the kernel density estimation curve of parameters $\phi_{12}$ and $\phi_{21}$ is quite smooth and varies with parameters, and each is in a single peak manner, which proves that the Monte Carlo estimation method, based on Gibbs sampling, effectively simulated the posterior distribution of the parameters in the model.

\section{Volatility spillovers in the stage of constant RMB shock \\ Convergence diagnosis}

After having finished the unit root test on these data, we used the GC-MSV model to empirically research volatility spillover effects between the foreign exchange and stock
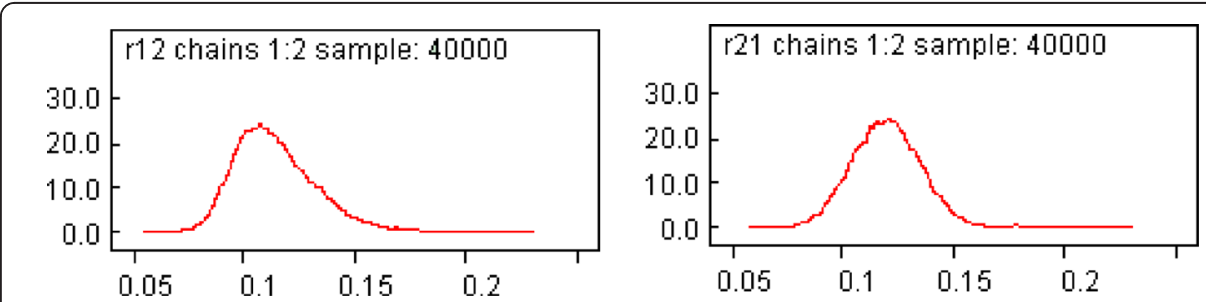

a) Kernel density estimation curve of $\phi_{12}$ b) Kernel density estimation curve of $\phi_{21}$

Fig. 1 Kernel density estimation curve of parameters $\phi_{12}$ and $\phi_{21}$ in the GC-MSV model 
market for the stage of constant RMB shock. Here, we also needed to test the convergence of the model parameters.

In the process of Gibbs sampling, we conducted a total of 40,000 iterations on the parameters, to ensure the convergence of parameters. We abandoned the former 20,000 iterative samples for annealing and stored the last 2000 iterative samples for parameter estimation. The Convergence diagnosis figures for the GR statistics of each parameter $\left(\mu_{1}, \mu_{2}, \phi_{11}, \phi_{22}, \phi_{12}, \phi_{21}, \rho_{\varepsilon}, \sigma_{\eta 1}, \sigma_{\eta 2}\right)$ indicate that each curve is stable and GR statistics for each parameter approach 1.0 with increasing iteration numbers. It implies that the samples reached convergence and can ensure the accuracy of parameter estimation.

\section{The estimation results and analysis}

After ensuring the convergence of model parameters, explanations could be given using the estimation results. The mean, standard deviation, MC-error, $2.5 \%$ fractile, median value and the $97.5 \%$ fractile of each parameter $\left(\mu_{1}, \mu_{2}, \phi_{11}, \phi_{22}, \phi_{12}, \phi_{21}, \rho_{\varepsilon}, \sigma_{\eta 1}, \sigma_{\eta 2}\right)$ in the GC-MSV model can be seen in Table 4. As can be seen in Table 4, the standard deviation and the $\mathrm{MC}$ error of each parameter are fairly small. This, once again, validates the convergence of the sample. The estimation results of parameters $\phi_{12}$ and $\phi_{21}$ are 0.9924 and 0.9419 , respectively, once again, proving the persistence of exchange rate changes and stock market volatility.

The volatility spillover effect from the stock market to the foreign exchange market was captured by the parameter $\phi_{12}$ with the estimated value of 0.0643 . Similarly, the volatility spillover effect from the exchange market to the stock market was captured by the parameter $\phi_{21}$ with the estimated value of 0.1143 . On the one hand, $\phi_{12}$ and $\phi_{21}$ have passed the convergence test and are significantly different from zero, which indicates that there is a tight linkage between stock return series and exchange rates in terms of the conditional secondary moments of relevant distributions, which is known as volatility spillovers. On the other hand, the estimated value of parameter $\phi_{12}$ is less than that of parameter $\phi_{21}$, implying that the influence of exchange rate fluctuations on the stock market is greater than the influence of stock price volatility on the foreign exchange market.

The conclusions drawn from the stage of constant RMB shock are generally consistent with that from the stage of continued RMB appreciation. The only difference between these was the fact that the mutual influence of the foreign exchange market and the stock market in the stage of constant RMB shock was not as strong as in the stage of continued RMB appreciation.

When estimating the parameters in the GC-MSV model, the posterior distribution kernel density estimation curve of the parameters $\left(\mu_{1}, \mu_{2}, \phi_{11}, \phi_{22}, \phi_{12}, \phi_{21}, \rho_{\varepsilon}, \sigma_{\eta 1}, \sigma_{\eta 2}\right)$ can also be obtained. We can see from Fig. 2 that the kernel density estimation curve

Table 4 Estimation results of parameters in the GC-MSV model

\begin{tabular}{lrllllllll}
\hline Parameters & $\mu_{1}$ & $\mu_{2}$ & $\phi_{11}$ & $\phi_{22}$ & \multicolumn{1}{l}{$\sigma_{\eta 1}$} & \multicolumn{1}{l}{$\sigma_{\eta 2}$} & \multicolumn{1}{l}{$\rho_{\varepsilon}$} & \multicolumn{1}{l}{$\phi_{12}$} & $\phi_{21}$ \\
\hline Mean & -6.1760 & 0.5218 & 0.9824 & 0.9419 & 0.1644 & 0.1778 & -0.1279 & 0.0643 & 0.1143 \\
Standard deviation & 0.4148 & 0.2813 & 0.0123 & 0.0280 & 0.0333 & 0.0481 & 0.0429 & 0.0189 & 0.0189 \\
MC error & 0.0194 & 0.0126 & 0.0001 & 0.0013 & 0.0018 & 0.0027 & 0.0001 & 0.0001 & 0.0001 \\
$2.5 \%$ fractile & -7.0080 & -0.0490 & 0.9519 & 0.8744 & 0.1165 & 0.1046 & -0.2108 & 0.0345 & 0.0845 \\
Median & -6.1690 & 0.5314 & 0.9850 & 0.9465 & 0.1580 & 0.1702 & -0.1282 & 0.0616 & 0.1116 \\
97.5\% fractile & -5.3960 & 1.0620 & 0.9982 & 0.9827 & 0.2510 & 0.2869 & -0.0427 & 0.1083 & 0.1583 \\
\hline
\end{tabular}




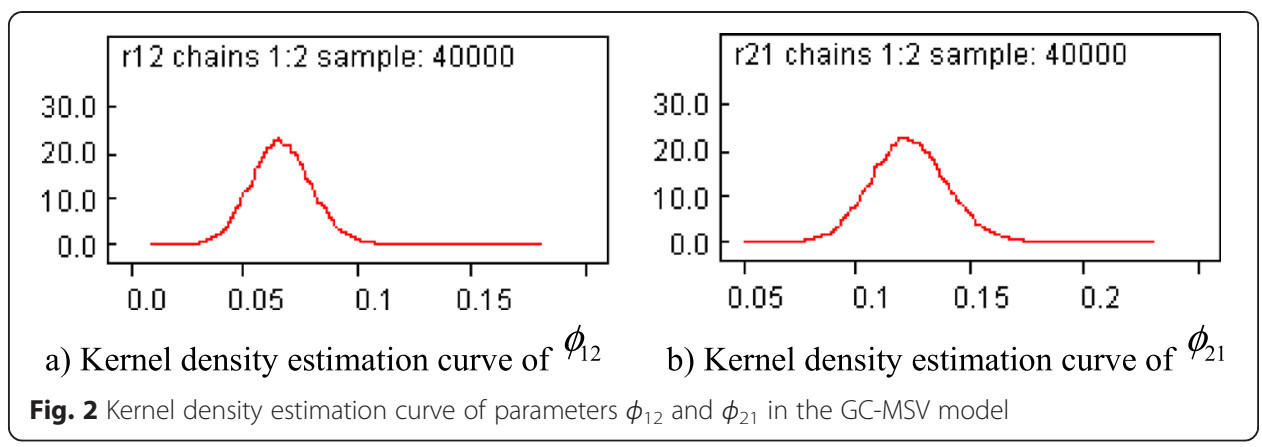

of parameters $\phi_{12}$ and $\phi_{21}$ are quite smooth and vary with parameters. Both are in a single peak manner, which once again proves that the Monte Carlo estimation method based on Gibbs sampling effectively simulated the posterior distribution of the parameters in the model.

\section{Conclusion}

As can be seen from the above empirical evidence, with changes in the RMB exchange rate movements, the spillover effects between the foreign exchange market and the stock market show different characteristics at different times. Concurrent with the current operational state of the financial markets, the following conclusions can be drawn:

(1) During the stage of continued RMB appreciation, the volatility spillover effects between the foreign exchange market and the stock market were bi-directional but asymmetric, with the volatility spillovers from the foreign exchange market to the stock market being more significant than from the stock market to the foreign exchange market. This phenomenon can be explained by the following points. First, after the exchange rate reform, the expectations of RMB appreciation brought a large number of international speculative capital inflows. Although strict controls are exercised over capital projects, massive international capital inflows that come from an informal pipeline can exert a large impact on the stock market and cannot be ignored. The input, or the withdrawal, of those funds would inevitably lead to volatility in domestic asset prices, and thus, enhance the stock market's sensitivity to currency fluctuations. Second, as our country's economy is highly dependent on imports and exports, fluctuations in the exchange rate will surely affect the operating performance of listed Chinese corporations, especially of the listed companies with high dependence on foreign trade. The quality of the enterprise operating performance would influence the company's share price and eventually led to increased sensitivity in the stock market to exchange rate fluctuations. Furthermore, the implementation of the current managed floating exchange rate regime and the strict control over capital accounts may, to some extent, have limited the exchange of stock market information with the foreign exchange market, thereby weakening the volatility spillover effects from the stock market to the foreign exchange market. For all reasons stated, we can explain why the spillover effect of the foreign exchange market was more prominent than the spillover effect of the stock market.

(2) In the stage of constant RMB shock, the volatility spillover effects between the foreign exchange and stock markets were still bi-directional and asymmetric. However, 
they were not as significant as in the stage of continued RMB appreciation. Some scholars believe that the spillover effects between these two markets would become progressively significant with increasing capital market reform and the continuous development of financial liberalization. However, it is the actual operations performance of the foreign exchange and stock markets that can test whether those theories and such reasoning are correct. The global stock market suffered a slump due to global financial crisis. At the same time, China effectively halted the trend of RMB appreciation in order to protect exports from greater decline. Consequently, the RMB/USD exchange rate began to shift from continuous appreciation to constant shocks to maintain the stability of the stock market. We have to take flexible measures to deal with emergencies while recognizing market-oriented trends in the financial markets. The government's strong regulation plays an important role in maintaining the stability of the stock market. However, the financial crisis dampened investor enthusiasm and confidence, and the expectation of RMB appreciation at this stage can no longer boost the stock market boom as fast as the earlier stage of continuous RMB appreciation. These days, as foreign demands for RMB appreciation intensifies, the airline industry is benefiting from the exchange rate advantage and is demonstrated an ascending trend. This further confirms the impact of the foreign exchange market on the stock market.

The RMB exchange rate is a key variable that can affect the internal and external equilibrium of the national economy in an open economic environment, and the stock market is capable of quickly reflecting subtle changes in the real economy. The information exchange mechanism between the two markets is dynamic and complicated. For the stability of the financial markets and the healthy and rapid development of national economy, the following policy recommendations are offered. First, the government should strengthen risk management in financial markets and improve the efficiency of financial supervision. The focus of our country's financial efforts should proceed with exchange rate management and regulation in an orderly manner and ensure the security and stability of our country's economy and financial markets. Under the expectation of $\mathrm{RMB}$ appreciation, relevant departments should strengthen the supervision of speculative funds to prevent large-scale hot money inflows from causing extensive shocks to the stock market. Second, the government should develop the RMB derivatives market and enrich risk aversion tools to secure the foreign exchange market. Presently, effective financial derivative hedging instruments are apparently insufficient in our country. Even worse, the government's regulation of the RMB exchange rate floating range in the foreign exchange market resulted in domestic companies not pay attention to the volatility in exchange rates and the worse trend toward currency risk aversion. As the reform of the RMB exchange rate mechanism continues, foreign exchange risk faced by Chinese enterprises is increasing and the demand for exchange rate hedging instruments along with it. Therefore, it is extremely urgent for our country to improve the RMB derivatives market, offer various financial derivative hedging tools, and improve enterprise risk awareness and risk management capabilities. Third, the government should make good use of RMB appreciation, which is a double-edged sword, and provide guidance for a healthy market to development. Presently, China's economy is running well. Further appreciation may have an impact on the export industry in short term. However, in the long term, this new round of exchange rate reform will be of great benefit to the restructuring of China's economy 
and the curbing of inflation expectations. If use this double-edged sword of RMB appreciation well, it can contribute significantly to the healthy and transparent exchange of inter-market information and ultimately achieve the goal of safe and stable operations in all our financial markets.

\section{Competing interests}

The authors declare that they have no competing interests.

\section{Authors' contributions}

XZD drafted the framework of this paper, participated in the theoretical analysis and revised the manuscript critically. $\mathrm{HLJ}$ is in charge of the review of literature, the acquisition and analysis of data. Both authors read and approved the final manuscript.

\section{Acknowledgements}

This paper is supported by four funding projects, including National Social Science Foundation of China, Funding Project of Education Ministry for the Development of Liberal Arts and Social Sciences, National Natural Science Foundation of China, Program for Changjiang Scholars and Innovative Research Team in University of Ministry of Education of China.

From the above four funding projects, the previous two were received by Xiong Zhengde, namely the first author of this paper, who is responsible for drafting manuscript and theoretical analysis; while the receiver of the third project and the last project are respectively Zhu Huiming and Ma Chaoqun, two professors of Business Administration School of Hunan University, they provided a part of funding support.

In addition, we appreciate the translation service provided by Zhang Yanyan and Li Can, two graduate students of Business Administration School of Hunan University; as well as the polishing service offered by your editorial department.

Received: 4 May 2015 Accepted: 18 June 2015

Published online: 17 August 2015

\section{References}

Alaganar VT, Bhar R (2007) Empirical properties of currency risk in country index portfolios. Q Rev Econ Finance 47:159-174

Bodnar GM, Gentry WM (1993) Exchange rate exposure and industry characteristics: evidence from Canada, Japan, and the USA. J Int Money Finance 12(1):29-45

Branson WH (1983) Macroeconomic determinants of real exchange risk in managing foreign exchange risk. Cambridge University Press, Cambridge, pp 103-120

Brooks S, Gelman A (1998) General methods for monitoring convergence of iterative simulations. J Comput Graph Stat $82: 470-488$

Chang HL, Su CW, Lai YC (2009) Asymmetric price transmissions between the exchange rate and stock market in Vietnam. Int Res J Financ Econ 23:104-113

Chen J, Naylor M, Lu X (2004) Some insights into the foreign exchange pricing puzzle: Evidence from a small open economy. Pac Basin Financ J 12:41-64

Chen Y, Chen L, Ludong L (2009) Research on spillover effect between exchange rate and stock market. J Manag Sci 3:104-112

Chi X, Li Z, Bo S (2012) Volatility spillover effect between foreign exchange market and stock market_— based on wavelet multi-resolution analysis of data after the exchange rate reform. J Syst Manag 1:13-21

Choi D (2009) Volatility spillovers between New Zealand stock market returns and exchange rate changes before and after the 1997 Asian financial crisis. Asian J Financ Account 1(2):106-117

Dornbusch R, Fischer S (1980) Exchange rates and the current account. Am Econ Rev 70(5):960-971

Kanas A (2000) Volatility spillover between stock returns and exchange rate changes: International evidence. J Bus Financ Account 27(3-4):447-467

Shusong B, Min Y (2009) The dynamic relationships between stock price and exchange rate_—_an empirical analysis based on Chinese market. Nankai Econ Stud 2:46-60

Suhong Y, Zhang S, Xin H (2003) A comparative study between SV model and GARCH model on their capability of describing financial time series. J Syst Eng 5:28-33

Taylor ST (1986) Modeling Financial Time Series. John Wiley and Sons, Chichester

Wong DKT, Li K (2010) Comparing the performance of relative stock return differential and real exchange rate in two financial crises. Appl Financ Econ 16(1):137-150

Xinling Z, Peng L (2011) Connected effect between RMB exchange rate and stock price-_-based on the perspectives of spillovers and dynamic correlation. Finan Theory Pract 5:8-12

Yang SY, Doong SC (2004) Price and volatility spillovers between stock prices and exchange rates: Empirical evidence from the G-7 countries. Int J Bus Econ 3(2):139-153

Zhizhen F, Xiuquan C (2010) Volatility spillovers and long-term linkage between exchange rate and stock price-an empirical study based on Chinese market after the exchange rate reform. Financ Theory Pract 1:91-95 